\title{
Preliminary evaluation of a robotic apparatus for the analysis of passive glenohumeral joint kinematics
}

\author{
Claudio Rosso ${ }^{2}$, Andreas M Müller ${ }^{2}$, Vahid Entezari ${ }^{1}$, William A Dow ${ }^{1}$, Brett McKenzie ${ }^{1}$, Stacey K Stanton ${ }^{1}$, Daniel Li ${ }^{1}$, \\ Andrea Cereatti ${ }^{2}$, Arun J Ramappa ${ }^{3}$, Joseph P DeAngelis ${ }^{3}$, Ara Nazarian ${ }^{1 *}$ and Ugo Della Croce $^{4}$
}

\begin{abstract}
Background: The shoulder has the greatest range of motion of any joint in the human body. This is due, in part, to the complex interplay between the glenohumeral $(\mathrm{GH})$ joint and the scapulothoracic (ST) articulation. Currently, our ability to study shoulder kinematics is limited, because existing models isolate the $\mathrm{GH}$ joint and rely on manual manipulation to create motion, and have low reproducibility. Similarly, most established techniques track shoulder motion discontinuously with limited accuracy.
\end{abstract}

Methods: To overcome these problems, we have designed a novel system in which the shoulder girdle is studied intact, incorporating both GH and ST motions. In this system, highly reproducible trajectories are created using a robotic actuator to control the intact shoulder girdle. High-speed cameras are employed to track retroreflective bone markers continuously.

Results: We evaluated this automated system's capacity to reproducibly capture GH translation in intact and pathologic shoulder conditions. A pair of shoulders (left and right) were tested during forward elevation at baseline, with a winged scapula, and after creation of a full thickness supraspinatus tear.

Discussion: The system detected differences in $\mathrm{GH}$ translations as small as $0.5 \mathrm{~mm}$ between different conditions. For each, three consecutive trials were performed and demonstrated high reproducibility and high precision.

Keywords: Shoulder biomechanics, Shoulder range of motion, Motion analysis, Glenohumeral joint

\section{Background}

The glenohumeral $(\mathrm{GH})$ joint has the greatest range of motion (ROM) of any joint in the human body. It benefits from both the humeral head motion in the glenoid and the scapular motion against the thorax. Given the limited articular congruency of the GH joint, the shoulder joint demonstrates little intrinsic stability, enjoys a tenuous relationship between motion and stability, and is easily injured [1].

In order to better understand the mechanisms of injury and establish appropriate treatment protocols for shoulder pathology, several biomechanical models have

\footnotetext{
* Correspondence: anazaria@bidmc.harvard.edu

${ }^{1}$ Center for Advanced Orthopaedic Studies, Beth Israel Deaconess Medical Center and Harvard Medical School, 330 Brookline Avenue, RN115, Boston, MA 02215, USA

Full list of author information is available at the end of the article
}

been developed. Many techniques study the GH joint in isolation, without consideration of scapulothoracic (ST) motion or the position of the clavicle [2-7]. Other methods rely on discrete and manual manipulation of the shoulder over a limited motion trajectory [8-11]. This methodology introduces significant errors in measurement, positioning, and reproducibility. Additionally, the approach simplifies shoulder motion, thereby negating its dynamic nature.

To improve upon current techniques, we have developed an automated testing apparatus that was designed to test the intact shoulder girdle and assess its kinematics with excellent reproducibly and high precision and accuracy $[12,13]$. This system manipulates an intact cadaveric torso using robotic technology to reproduce patterns of motion for the upper extremity. Motion data are captured continuously using retroreflective bone

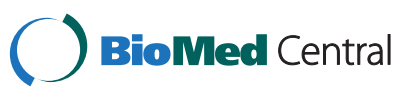


markers for continuous stereophotogrammetric analysis. Therefore, the goal of this study was to assess the reproducibility of the presented automated techniques and kinematic analysis of $\mathrm{GH}$ translation during forward elevation of the $\mathrm{GH}$ joint in cadaveric tissue.

\section{Methods}

\section{Testing apparatus}

A robotic testing system that generates automated motion segments for a cadaveric torso over a designated trajectory was designed and manufactured (Figure 1). The robotic system consists of lower (torso) and upper (hand) frames that provide linear and rotational motion along seven axes. The lower frame generates motion along $X, Y$, and $Z$ axes and around the $Z$-axis while the upper frame generates motion along the $X, Y$, and $Z$ axes. Motion is generated using linear and rotary closed loop actuators that are controlled via a centralized programmable system to generate any motion trajectory within the actuators' limits. Limit and home switches are combined with encoders to produce closed loop feedback for each axis, ensuring safety and precision. The precision and accuracy of the testing system in reproducing pure and complex trajectories have been established in a separate publication [13].

A fresh frozen human torso was acquired from Medcure Anatomical Tissue Bank (Orlando, FL, USA). The torso was mounted onto a rod fixture and held in place with volume expanding foam to provide a support construct. After securing the torso to its frame, the hand was removed at the distal radioulnar joint (wrist disarticulation), and the arm was secured directly to the upper frame using a Schanz pin (Synthes, Paoli, PA, USA) inserted through the radius and the ulna. In order to test the GH translation, forward elevation motion was simulated in the sagittal, scapular, and coronal planes.

\section{Motion analysis}

Five Qualisys ProReflex (Qualisys AB, Gothenburg, Sweden) high-speed cameras (120 frames per second) were used to record the motion of passive retroreflective, bone-embedded marker clusters (four markers/cluster for redundancy). Prior to testing, the cameras underwent a multiaspect calibration process to ensure accurate data collection, enabling them to discern motion segments as small as $0.5 \mathrm{~mm}$. Bone pins equipped with marker clusters were inserted into the humerus, scapula, and thorax of the cadaver. Anatomical landmarks were calibrated with respect to the boneembedded marker clusters using a point wand technique at locations defined by the International Society of Biomechanics (ISB) $[14,15]$. These data were used to create a reference coordinate system for the scapula (Figure 2). The calibrated landmarks were used to locate the center of motion for the $\mathrm{GH}$ joint according to Meskers et al. [16]. The translation of the GH center of motion was described using the scapular coordinate system in reference to the resting position of the arm (arm hanging along the side of the torso).

\section{Cadaveric proof of concept}

Two shoulders from one cadaveric torso from a healthy subject with a body mass index of 35.3 and humerus length of $305 \mathrm{~mm}$ were tested. All motions were recorded in three trials. First, forward elevation was simulated by moving the intact arm from $0^{\circ}$ to $160^{\circ}$ of abduction in the coronal plane. The same motion was then repeated when the scapula was winged (reversible perturbation). The efficacy of this model of scapular winging has been illustrated in a previous investigation demonstrating its internal validity and reversibility [17]. In brief, the inferior medial angle of the scapula was elevated away from the thorax by attaching a cylindrical

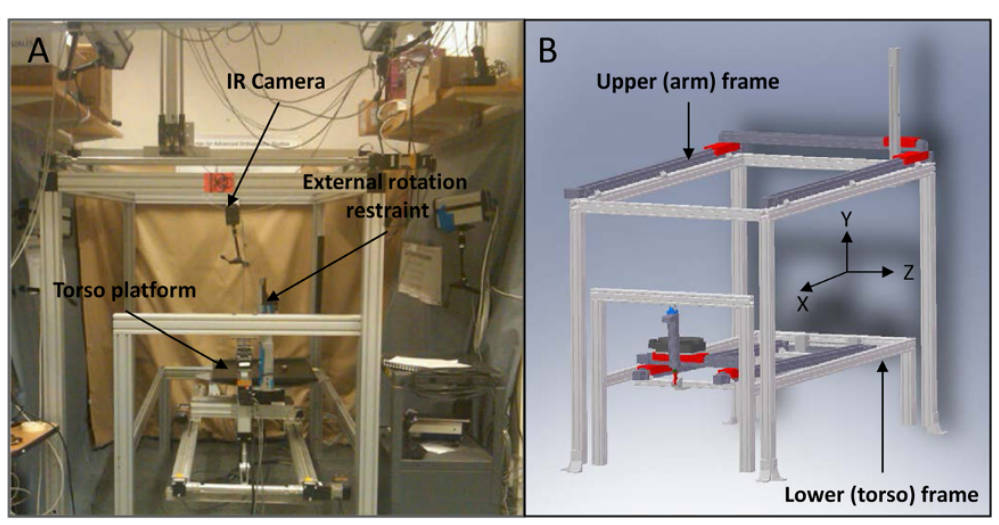

Figure 1 Robotic testing system that generates automated motion segments for a cadaveric torso over a designated trajectory. The seven degrees of freedom testing apparatus was designed and manufactured with four actuators on the lower frame to move the torso and three actuators on the upper frame to move the hand with an additional rotational axis added to the lower frame to rotate the torso. (A) Apparatus photograph. (B) Apparatus schematic. 


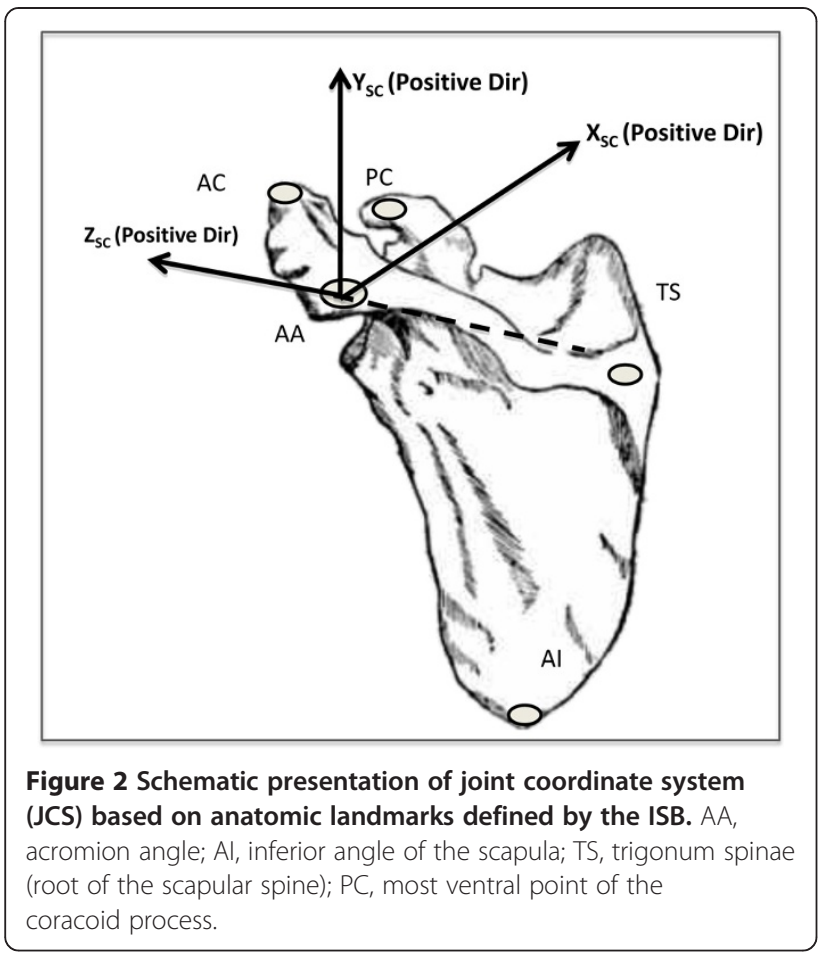

wedge ( $24 \mathrm{~mm}$ in height and $50 \mathrm{~mm}$ in diameter) to the underside of the scapula. Once secured to the bone, scapulothoracic motion was unencumbered. To restore the native state and illustrate the model reversibility, the wedge was removed and the scapula was allowed to return to its resting position. The forward and abduction motions were repeated.

The specimen was then subjected to forward elevation motion from $0^{\circ}$ to $160^{\circ}$ of abduction, this time in the scapular plane. After three repetitions using the intact specimen, a full thickness tear $(3 \mathrm{~cm}$ anterior to posterior) of the supraspinatus tendon was created, and the motion was tested in this pathologic state (irreversible perturbation). The rotator cuff tear was then repaired using a transosseous-equivalent (double row) technique by board-certified orthopedic surgeons (AJR and JPD), and forward elevation was repeated. This process was repeated on the other shoulder of the cadaveric torso.

\section{Statistical analysis}

The captured motion was divided into ten equal time intervals with the same number of frames. The average $\mathrm{GH}$ translations in $X, Y$, and $Z$ axes were normalized to the baseline values of the native case in the intact shoulder case. In order to demonstrate the precision of the testing apparatus in measuring $\mathrm{GH}$ translations, the standard error of the mean (SEM) and intraclass correlation coefficient (ICC) for the average GH translation in $X, Y$, and $Z$ axes were reported for scapular winging and the supraspinatus tear and repair conditions. A repeated measures ANOVA with Greenhouse-Geisser correction was used to test the difference in mean GH translation at baseline (BL), scapular winging (SW) and restored scapular (RS) positions and between BL, ST and supraspinatus repair (SR) positions. A post hoc analysis with Bonferroni correction was used to analyze the differences between testing conditions. Data analysis was performed using SPSS statistical software (version 21.0; IBM, Armonk, NY, USA), and statistical significance level was set at $P$ value $<0.05$.

\section{Results}

During three sequential trials of forward elevation of the arm at baseline, and after winging and subsequently restoring the scapula, the $\mathrm{GH}$ translation was recorded with standard error of the mean of 0.02 to $0.06 \mathrm{~mm}$ and intraclass correlation coefficient of 0.99 to 1.00 ( $P$ values $<0.001$ ) for all three axes (Table 1). Glenohumeral translation was also recorded after subjecting the arm to the same forward elevation motion at baseline and after supraspinatus tear and repair that resulted in SEM of 0.0 to $0.2 \mathrm{~mm}$ and ICC ranging from 0.86 to 1.00 ( $P$ values $<0.001$ ) (Table 2).

The testing system was capable of discerning $\mathrm{GH}$ translation between baseline and reversible scapular winging conditions. Winging the scapula resulted in an average $1.6 \mathrm{~mm}$ medial translation ( $Z$-axis) of the humeral head compared to that of the baseline $(P<0.001)$ during forward elevation of the arm (Figure $3 C$ ), while the difference was not statistically significant for $X$ and $Y$ axes ( $P$ values were 0.10 and 0.32 , respectively) (Figure 3A,B,C, Table 1). As shown in Figure 3A,B,C, $\mathrm{GH}$ translations for forward elevation following the restoration of the scapular winging were similar to those of the baseline for all three axes.

The effects of supraspinatus tear and repair on $\mathrm{GH}$ translation are depicted in Figure 4A,B,C. During forward elevation, $\mathrm{GH}$ translation was not significantly different between baseline and supraspinatus tear conditions (Table 2), while supraspinatus repair on average resulted in $2.2 \mathrm{~mm}(0.2$ to $4.2 \mathrm{~mm})$ anterior translation, $2.5 \mathrm{~mm}(0.7$ to $5.8 \mathrm{~mm})$ inferior translation, and $2.9 \mathrm{~mm}$ (1.1 to $4.6 \mathrm{~mm}$ ) medial translation of the $\mathrm{GH}$ joint in comparison to the supraspinatus tear condition ( $P$ values were $0.01,0.048$, and 0.001 respectively). Supraspinatus repair had a more profound effect on GH translation in the $0^{\circ}$ to $60^{\circ}$ range of forward elevation (Figure 4A,B,C).

\section{Discussion}

The aim of this study was to evaluate a novel robotic system to analyze passive shoulder kinematics. To that end, we recorded GH translations during shoulder forward elevation of a cadaveric model before and after the 
Table 1 Baseline, scapular winging, and restored scapula

\begin{tabular}{|c|c|c|c|c|c|c|c|}
\hline Axis & Direction & Conditions & Mean & SD & SEM $(95 \% \mathrm{Cl})$ & ICC (95\% CI) & $P$ value \\
\hline \multirow[t]{3}{*}{$x$} & Anterior (+)/Posterior (-) & $B L$ & 2.5 & 1.4 & 0.07 (0.02 to 0.27$)$ & 0.999 (0.996 to 0.100$)$ & 0.10 \\
\hline & & SW & 2.4 & 1.4 & 0.03 (0.01 to 0.18 ) & 0.999 (0.998 to 0.100$)$ & \\
\hline & & RS & 2.1 & 1.2 & 0.04 (0.01 to 0.17 ) & 0.999 (0.998 to 0.100$)$ & \\
\hline \multirow[t]{3}{*}{ Y } & Superior $(+) /$ Inferior $(-)$ & $B L$ & -1.4 & 1.2 & 0.03 (0.02 to 0.12 ) & 0.999 (0.998 to 0.100$)$ & 0.32 \\
\hline & & SW & -1.1 & 0.9 & 0.07 (0.04 to 0.41$)$ & 0.993 (0.978 to 0.998$)$ & \\
\hline & & RS & -1.3 & 1.1 & 0.05 (0.04 to 0.25$)$ & 0.997 (0.992 to 0.99.9) & \\
\hline \multirow[t]{3}{*}{$z$} & Lateral (-)/Medial(+) & $B L$ & -4.5 & 2.6 & 0.04 (0.01 to 0.18 ) & 0.100 (0.100 to 0.100$)$ & $<0.001^{\mathrm{a}}$ \\
\hline & & SW & -2.9 & 2.6 & 0.06 (0.01 to 0.36$)$ & 0.999 (0.998 to 0.100$)$ & \\
\hline & & RS & -4.4 & 2.7 & 0.05 (0.05 to 0.12$)$ & 0.100 (0.999 to 0.100$)$ & \\
\hline
\end{tabular}

${ }^{a}$ Statistical significance. The mean, standard deviation (SD), standard error of the mean (SEM), intraclass correlation coefficient (ICC), and its $95 \%$ confidence interval $(\mathrm{Cl})$ of glenohumeral translations after three trials of humeral elevation from $0^{\circ}$ to $160^{\circ}$ at baseline (BL) and after scapular winging (SW) and restored scapula (RS) are summarized here in this table.

implementation and restoration of two fundamentally different shoulder lesions that either directly involved or were distant to the GH joint. The trajectories obtained from the same cadaver at baseline and after the implementation and restoration of a specific shoulder pathology showed high reliability with an intraclass correlation coefficient of 0.82 to 1.00 and standard error of mean of 0.02 to 0.23 . The system was able to detect small changes in glenohumeral translations that were caused by creation and elimination of scapular winging and supraspinatus tear and repair as two clinically relevant models.

The GH joint kinematics was affected differently by scapular winging than the torn rotator cuff. Removal of the wedge from underneath the scapula returned the pattern of motion back to its baseline. In contrast, the change associated with the torn rotator cuff was not corrected when it was repaired. This effect is seen in the overlap of the baseline and restored scapular winging trajectories, while the rotator cuff tear and repaired states are substantially different. Any inference on the efficacy of current rotator cuff repairs from a biomechanical standpoint are outside the scope of this study.

The kinematics of the shoulder joint have been studied using both in vivo and ex vivo studies. The advantage of in vivo investigations, as compared to our proposed system, is the contribution of active muscle forces that results in a natural motion pattern and dynamic stabilization of the $\mathrm{GH}$ joint. On the other hand, in vivo studies offer limited control and display low inter- and intrasubject reliability due to fatigue and pain $[9,18-20]$, yet they provide accurate active loading scenarios that cannot be duplicated in ex-vivo settings. In addition, the accuracy of current approaches to track motions in vivo is limited. Currently, the two most common modalities, stereophotogrammetry and electromagnetic tracking, use skin markers with limited capacity to accurately record the movement of the underlying bony structures [21]. Some studies have used bone-embedded markers to overcome the error imparted by skin motion $[18,20,21]$. However, rigid markers in live subjects are associated with a risk of infection, change in pattern of

Table 2 Baseline, supraspinatus tear, and supraspinatus repair

\begin{tabular}{|c|c|c|c|c|c|c|c|}
\hline Axis & & Conditions & Mean & SD & SEM $(95 \% \mathrm{Cl})$ & ICC (95\% Cl) & $P$ value \\
\hline \multirow[t]{3}{*}{$x$} & Anterior (+)/Posterior (-) & $\mathrm{BL}$ & 0.9 & 1.3 & 0.07 (0.04 to 0.52$)$ & 0.994 (0.975 to 0.998$)$ & $\overline{0.01^{\mathrm{a}}}$ \\
\hline & & ST & 0.09 & 0.9 & 0.23 (0.04 to 0.86$)$ & 0.816 (0.259 to 0.954$)$ & \\
\hline & & SR & 2.3 & 2.2 & 0.05 (0.01 to 0.28$)$ & 0.999 (0.997 to 0.100$)$ & \\
\hline \multirow[t]{3}{*}{ Y } & Superior (+)/Inferior (-) & $B L$ & 0.7 & 1.7 & 0.02 (0.01 to 0.18$)$ & 0.100 (0.998 to 0.100$)$ & $0.048^{\mathrm{a}}$ \\
\hline & & ST & 0.6 & 1.7 & 0.02 (0.01 to 0.07$)$ & 0.100 (0.999 to 0.100$)$ & \\
\hline & & SR & -1.9 & 5.0 & $0.04(0.01$ to 0.31$)$ & 0.100 (0.999 to 0.100$)$ & \\
\hline \multirow[t]{3}{*}{$z$} & Lateral (-)/Medial (+) & $\mathrm{BL}$ & -2.5 & 1.9 & $0.04(0.01$ to 0.16$)$ & 0.100 (0.999 to 0.100$)$ & $0.001^{\mathrm{a}}$ \\
\hline & & ST & -2.6 & 2.1 & 0.02 (0.01 to 0.08$)$ & 0.100 (0.100 to 0.100$)$ & \\
\hline & & SR & -5.4 & 1.2 & 0.03 (0.01 to 0.15$)$ & 0.999 (0.996 to 0.100$)$ & \\
\hline
\end{tabular}

${ }^{a}$ Statistical significance. The mean, standard deviation (SD), standard error of the mean (SEM), intraclass correlation coefficient (ICC) and its $95 \%$ confidence interval $(\mathrm{Cl})$ of glenohumeral translations after three trials of humeral elevation from $0^{\circ}$ to $160^{\circ}$ at baseline (BL) and after supraspinatus tear (ST) and supraspinatus repair (SR) are summarized here in this table. 


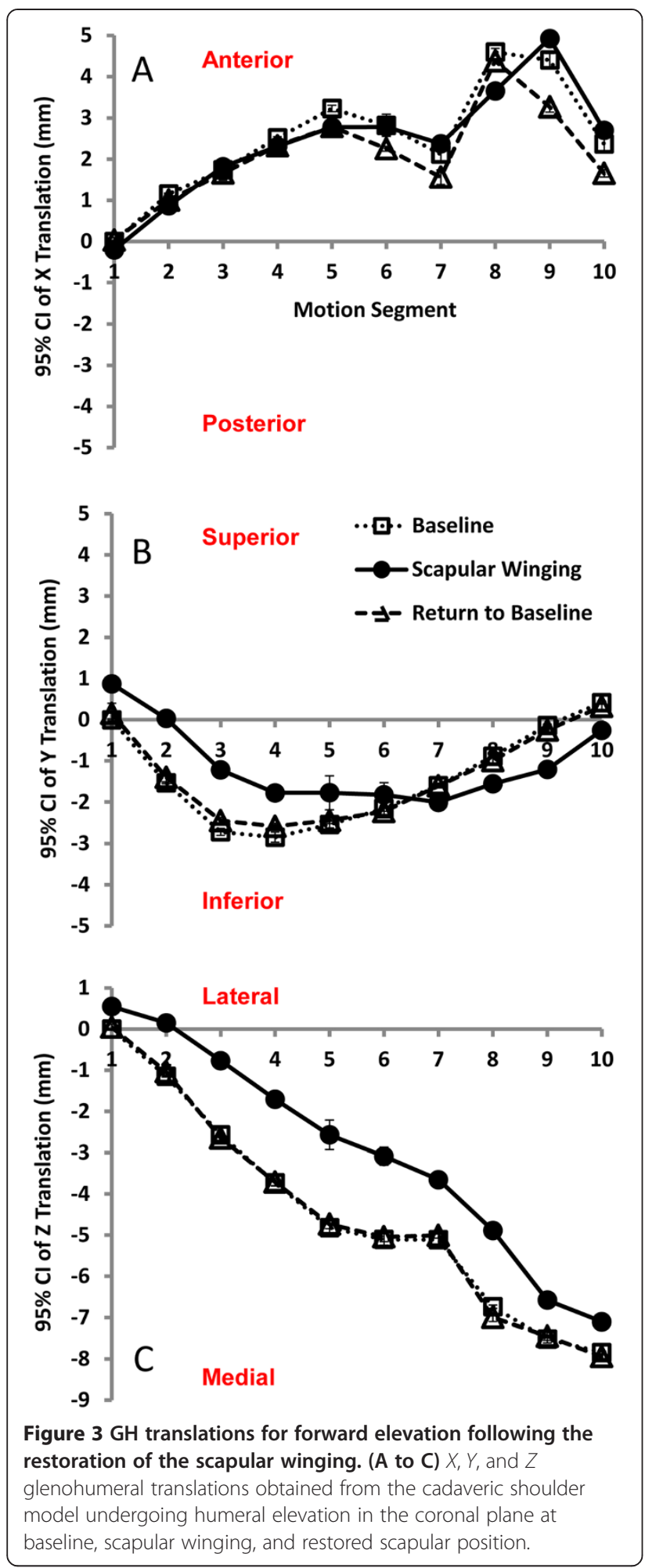

motion due to pain, and translational/rotational instability of the actual pin [18]. Recent in vivo investigations have moved from tracking of markers to the use of CT and fluoroscopy for 3D tracking to 2D motion tracking,
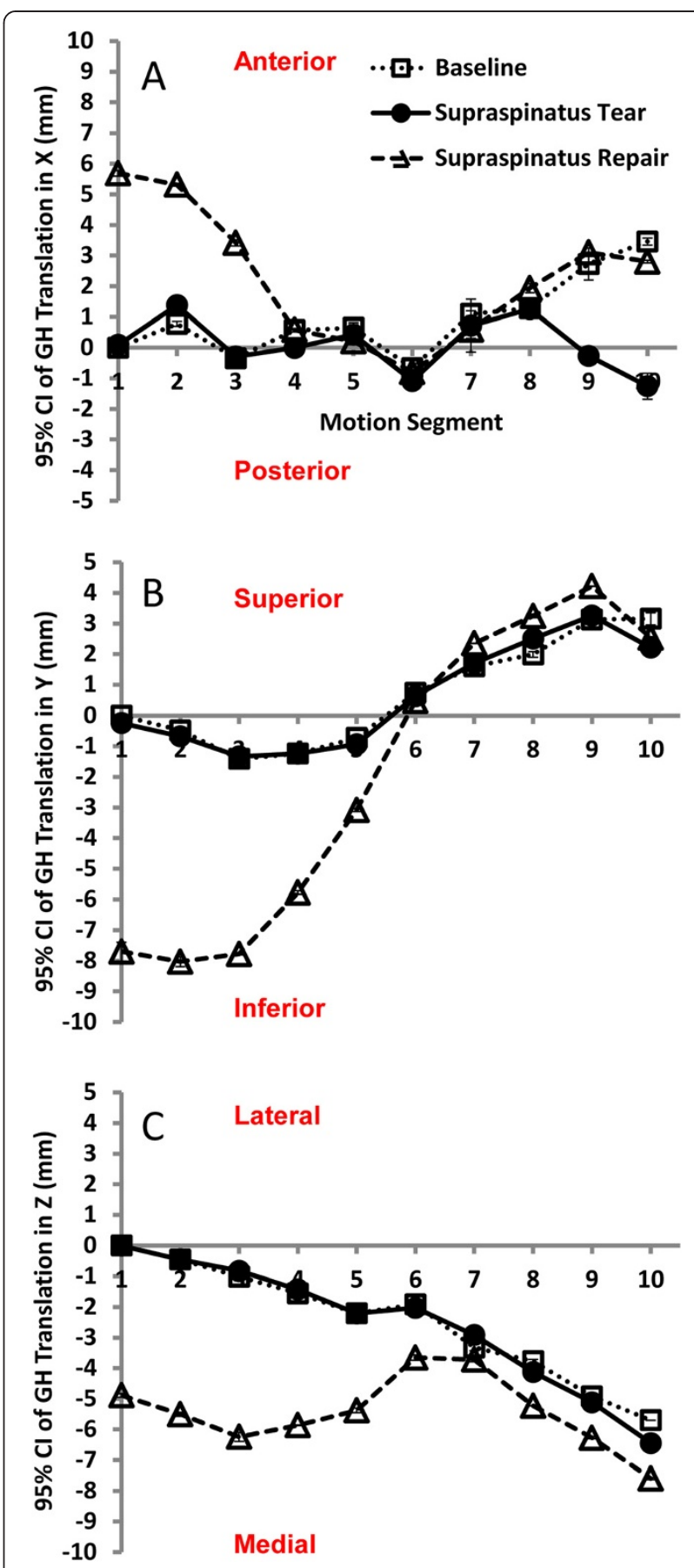

Figure $4 \mathrm{GH}$ translation in the $0^{\circ}$ to $60^{\circ}$ range of forward elevation. (A to $\mathbf{C}) X, Y, Z$ glenohumeral translations obtained from the cadaveric shoulder model undergoing humeral elevation in the scapular plane at baseline and after supraspinatus tear and repair.

with the main limitations being radiation-exposed $[22,23]$.

Previous ex vivo shoulder kinematic analyses including finite element analysis [24] and cadaveric modeling $[8,11,25-29]$ have shown similar constraints as the proposed system with the elimination of the muscles as 
dynamic stabilizers of the GH joint. In some studies, loading the tendons of the selected muscles or muscle groups was simulated, but this adaptation is technically demanding for dynamic motions and is applied best on a small scale with a limited number of joints in question. Previous ex vivo studies have also shown high intersubject variability as observed in this study. The major improvement of this testing system over the current ex vivo methods is its ability to study the entire shoulder girdle (including the scapulothoracic, acromioclavicular, and sternoclavicular joints) and to reproduce a wide variety of basic and complex shoulder motions with high accuracy and precision, while allowing for real-time data acquisition. Moreover, the proposed system is capable of following an exact motion trajectory throughout all steps of the test. Nonetheless, the interaction of the apparatus, the marker clusters, and the cameras can affect the visibility of the markers and requires careful planning and operation.

There are a number of limitations associated with this preliminary study. First of all, the speed of the simulated shoulder motion was much lower than that usually observed in human subjects. This was done to avoid any unintended damage to the cadaver. While humeral elevation speed was shown to alter GH biomechanics [26] in active shoulder models, it remains unclear whether these findings can be transferred to passive cadaveric models. However, it was beyond the scope of this study to explore the association between motion speed and GH kinematics in our model. Nevertheless, this could be clarified in future studies. We included one cadaveric shoulder and demonstrated the effects of the implementation and restoration of only two shoulder pathologies with respect to the intact condition. The scapular winging condition may stand for all pathologies that are distant to the GH joint but are capable of affecting GH translations, while the rotator cuff tear may represent all pathologies that are intrinsic to the joint and can directly affect its translations. Had we not restricted this study to the analysis of these two characteristic pathologies, then the number of lesions up for debate would have easily exceeded the boundaries of an evaluation study.

Given the limited feedback on leverage forces effectively applied by the actuator to the GH joint with no dynamic stabilization of the joint by muscle forces, the extent of joint translations may vary among anthropometrically different specimens. Cadaver-specific tissue elasticity accentuated after the thawing process may further contribute to the observed interspecimen variability. There is also an inherent variability associated with the calibration of the anatomical landmarks in each specimen using a pointing wand, since these landmarks are areas rather than discrete points [29]. Nevertheless, our data indicate that changes in translation from one condition to the other may be quite consistent among different shoulders, particularly if specific segments of a motion are analyzed. Therefore, future studies may primarily compile between-condition changes observed in different specimens and subject these to paired comparative statistical tests.

\section{Conclusion}

In conclusion, we have shown that the presented cadaveric, stereophotogrammetric testing system is capable of differentiating GH translations in sequential clinical conditions over a series of repetitions with a high degree of reproducibility in cadaveric tissue. These results confirm that this dynamic testing apparatus could be used to study cadaveric shoulder kinematics and simulate relevant clinical scenarios.

\section{Competing interests}

The authors declare that they have no competing interests.

\section{Authors' contributions}

$C R, A M, V E, W D, B M, S S$, and DL contributed towards data acquisition, data analysis, manuscript preparation, and final approval. UD and AC contributed towards data analysis, manuscript preparation, and final approval. AR, JD, and AN contributed towards study design, data acquisition, surgical procedures, manuscript preparation, and final approval. All authors read and approved the final manuscript.

\section{Acknowledgements}

The authors would like to acknowledge the Medical Advisory Committee for Major League Baseball (AJR and AN) and the Department of Orthopaedic Surgery at Beth Israel Deaconess Medical Center, Boston, MA (AN and AJR) for funding this project. They would like to gratefully acknowledge the National Institute of Health (L30 AR056606) for providing funding to AN, the Swiss National Science Foundation for providing funding to CR and AMM, and the Swiss Orthopaedic Society for providing support to CR to work on this project. They would also like to acknowledge the efforts of Mr. Dan India and the technical staff at Qualisys, AB and Dr. Glenn Fleisig and his team from the American Sports Medicine Institute for their help with the motion analysis component of the project.

\section{Author details}

${ }^{1}$ Center for Advanced Orthopaedic Studies, Beth Israel Deaconess Medical Center and Harvard Medical School, 330 Brookline Avenue, RN115, Boston, MA 02215, USA. ${ }^{2}$ Orthopaedic Department, University Hospital Basel, University of Basel, Basel, Switzerland. ${ }^{3}$ Department of Orthopaedic Surgery, Beth Israel Deaconess Medical Center, Harvard Medical School, Boston, MA 02115, USA. ${ }^{4}$ Department of Information Engineering, Political Sciences and Communication Sciences, University of Sassari, Sassari 07100, Italy.

Received: 25 March 2013 Accepted: 15 July 2013

Published: 24 July 2013

\section{References}

1. Apreleva M, Hasselman CT, Debski RE, Fu FH, Woo SL, Warner JJ: A dynamic analysis of glenohumeral motion after simulated capsulolabral injury. A cadaver model. J Bone Joint Surg Am 1998, 80:474-480.

2. Howell SM, Galinat BJ: The glenoid-labral socket. A constrained articular surface. Clin Orthop Relat Res 1989, 243:122-125.

3. Ovesen J, Nielsen S: Stability of the shoulder joint. Cadaver study of stabilizing structures. Acta Orthop Scand 1985, 56:149-151.

4. Thomas SJ, Swanik CB, Higginson JS, Kaminski TW, Swanik KA, Bartolozzi AR, Abboud JA, Nazarian LN: A bilateral comparison of posterior capsule thickness and its correlation with glenohumeral range of motion and scapular upward rotation in collegiate baseball players. J Shoulder Elbow Surg 2011, 20:708-716. 
5. Thomas SJ, Swanik KA, Swanik CB, Kelly JD: Internal rotation and scapular position differences: a comparison of collegiate and high school baseball players. J Athl Train 2010, 45:44-50

6. Della Croce U, Leardini A, Chiari L, Cappozzo A: Human movement analysis using stereophotogrammetry. Part 4: assessment of anatomical landmark misplacement and its effects on joint kinematics. Gait Posture 2005, 21:226-237.

7. Lippitt S, Matsen F: Mechanisms of glenohumeral joint stability. Clin Orthop Relat Res 1993, 291:20-28.

8. Hatakeyama Y, Itoi E, Pradhan RL, Urayama M, Sato K: Effect of arm elevation and rotation on the strain in the repaired rotator cuff tendon. A cadaveric study. Am J Sports Med 2001, 29:788-794.

9. McClure PW, Michener LA, Sennett BJ, Karduna AR: Direct 3-dimensional measurement of scapular kinematics during dynamic movements in vivo. J Shoulder Elbow Surg 2001, 10:269-277.

10. van Andel C, van Hutten K, Eversdijk M, Veeger D, Harlaar J: Recording scapular motion using an acromion marker cluster. Gait Posture 2009, 29:123-128.

11. Zuckerman JD, Leblanc JM, Choueka J, Kummer F: The effect of arm position and capsular release on rotator cuff repair: a biomechanical study. J Bone Joint Surg Br 1991, 73:402-405.

12. Miyakoshi N, Shimada Y, Suzuki T, Hongo M, Itoi E: Magnetic resonance imaging of spinal involvement by hematopoietic malignancies requiring surgical decompression. J Orthop Sci 2003, 8:207-212.

13. Entezari V, Trechsel BL, Dow WA, Stanton SK, Rosso C, Mueller AM, McKenzie B, Vartanians V, Cereatti A, Della Croce U, DeAngelis JP, Ramappa AJ, Nazarian A: Design and manufacture of a novel system to simulate the real time biomechanics of basic and pitching shoulder motion using a cadaveric model. Bone and Joint Research 2012, 1:78-85.

14. Chiari L, Della Croce U, Leardini A, Cappozzo A: Human movement analysis using stereophotogrammetry. Part 2: instrumental errors. Gait Posture 2005, 21:197-211.

15. Liu J, Hughes RE, Smutz WP, Niebur G, Nan-An K: Roles of deltoid and rotator cuff muscles in shoulder elevation. Clin Biomech (Bristol, Avon) 1997, 12:32-38.

16. Meskers CG, Fraterman $\mathrm{H}$, van der Helm FC, Vermeulen HM, Rozing PM: Calibration of the "Flock of Birds" electromagnetic tracking device and its application in shoulder motion studies. J Biomech 1999, 32:629-633.

17. Mueller AM, Entezari V, Rosso C, McKenzie B, Hasebroock A, Della Croce U, DeAngelis JP, Nazarian A, Ramappa AJ: The effect of simulated scapular winging on glenohumeral translations. J Shoulder Elbow Surg 2013, 22:986-992.

18. Urayama M, Itoi E, Sashi R, Minagawa H, Sato K: Capsular elongation in shoulders with recurrent anterior dislocation. Quantitative assessment with magnetic resonance arthrography. Am J Sports Med 2003, 31:64-67.

19. Kikuchi K, Itoi E, Yamamoto N, Seki N, Abe H, Minagawa H, Shimada Y: Scapular inclination and glenohumeral joint stability: a cadaveric study. J Orthop Sci 2008, 13:72-77.

20. Park SS, Loebenberg ML, Rokito AS, Zuckerman JD: The shoulder in baseball pitching: biomechanics and related injuries-part 2. Bull Hosp Jt Dis 2002, 61:80-88.

21. Leardini A, Chiari L, Della Croce U, Cappozzo A: Human movement analysis using stereophotogrammetry. Part 3. Soft tissue artifact assessment and compensation. Gait Posture 2005, 21:212-225.

22. Park SS, Loebenberg ML, Rokito AS, Zuckerman JD: The shoulder in baseball pitching: biomechanics and related injuries-part 1. Bull Hosp Jt Dis 2002, 61:68-79.

23. Weiser WM, Lee TQ, McMaster WC, McMahon PJ: Effects of simulated scapular protraction on anterior glenohumeral stability. Am J Sports Med 1999, 27:801-805.

24. Lee SB, Kim KJ, O'Driscoll SW, Morrey BF, An KN: Dynamic glenohumeral stability provided by the rotator cuff muscles in the mid-range and end-range of motion. A study in cadavera. J Bone Joint Surg Am 2000, 82:849-857.

25. Miyakoshi N, Itoi $\mathrm{E}$, Murai $\mathrm{H}$, Wakabayashi I, Ito $\mathrm{H}$, Minato T: Inverse relation between osteoporosis and spondylosis in postmenopausal women as evaluated by bone mineral density and semiquantitative scoring of spinal degeneration. Spine (Phila Pa 1976) 2003, 28:492-495.

26. Itoi $E$, Lee SB, Amrami KK, Wenger DE, An KN: Quantitative assessment of classic anteroinferior bony Bankart lesions by radiography and computed tomography. Am J Sports Med 2003, 31:112-118.
27. Myers JB, Laudner KG, Pasquale MR, Bradley JP, Lephart SM: Scapular position and orientation in throwing athletes. Am J Sports Med 2005, 33:263-271.

28. Baeyens JP, Van Roy P, De Schepper A, Declercq G, Clarijs JP: Glenohumeral joint kinematics related to minor anterior instability of the shoulder at the end of the late preparatory phase of throwing. Clin Biomech (Bristol, Avon) 2001, 16:752-757.

29. Cappozzo A, Della Croce U, Leardini A, Chiari L: Stereophotogrammetry. Part 1: theoretical background. Gait Posture 2005, 21:186-196.

doi:10.1186/1749-799X-8-24

Cite this article as: Rosso et al:: Preliminary evaluation of a robotic apparatus for the analysis of passive glenohumeral joint kinematics. Journal of Orthopaedic Surgery and Research 2013 8:24.

\section{Submit your next manuscript to BioMed Central and take full advantage of:}

- Convenient online submission

- Thorough peer review

- No space constraints or color figure charges

- Immediate publication on acceptance

- Inclusion in PubMed, CAS, Scopus and Google Scholar

- Research which is freely available for redistribution

Submit your manuscript at www.biomedcentral.com/submit

C BioMed Central 